\title{
Study of PT Fuse in Grounding Systems with the Harmonic Elimination Resistor
}

\author{
Yang Yongbo \\ State Grid Henan Electric Power Company \\ Zhengzhou Henan, China
}

\author{
Wang Maozhou, Wang Xiaoliang, Ai Xueyong \\ State Grid Henan Electric Power C \\ Zhengzhou Henan, China
}

\begin{abstract}
The removal of single-phase grounding fault in the $10 \mathrm{kV}$ distribution system caused voltage transformer fuse. Used Multisim simulation to modeling analysis, and discusses the harmonic elimination resistor in the lowfrequency oscillations of the current. With the proposed solutions, the research results have practical value and academic value.
\end{abstract}

Keywords-The Single-phase Grounding Fault; Fuse; Voltage Transformer; Multisim

\section{INTRODUCTION}

With the rapid development of China's economy, the demand for electricity is increasing, and transmission and distribution capacity is expanding. Distribution network with a complex operating environment, are prone to failure characteristics. In $10 \mathrm{kV}$ distribution system, VT (voltage transformer) frequently blown phenomenon. VT high voltage fuse blown cause various effects on the grid. VT generated resonance over-voltage may damage the insulation of other devices, breakdown other weak insulation on the bus, and cause serious short circuit, resulting in a large area blackout. If the high voltage fuse is blown, you cannot measure the voltage of $10 \mathrm{kV}$, a direct result of power calculation error. VT high voltage fuse protection insurance protection failure cause, seriously jeopardize the safety of the power grid. In order to ensure safe and reliable operation of the power grid, it is necessary to analyze the causes of VT fuse [1].

Currently, studies show that the cause of the blown VT are as follow. First, the operation mode switching system, causing VT produce ferromagnetic resonance. Second is a system of $10 \mathrm{kV}$ single-phase ground fault occurs, resulting arc grounding over-voltage. Third is secondary overload will cause excessive current VT. Fourth, low-frequency saturation current operations generated. Fifth, a voltage transformer secondary winding insulation is reduced.

\section{ACCIDENT PHENOMENON}

Operating mode of $110 \mathrm{kV}$ substation in one city is one single transformer with $10 \mathrm{kV}$ I bus system, and the neutral point of the system with not-grounded. On-site inspection equipment operation shows in Figure 1:

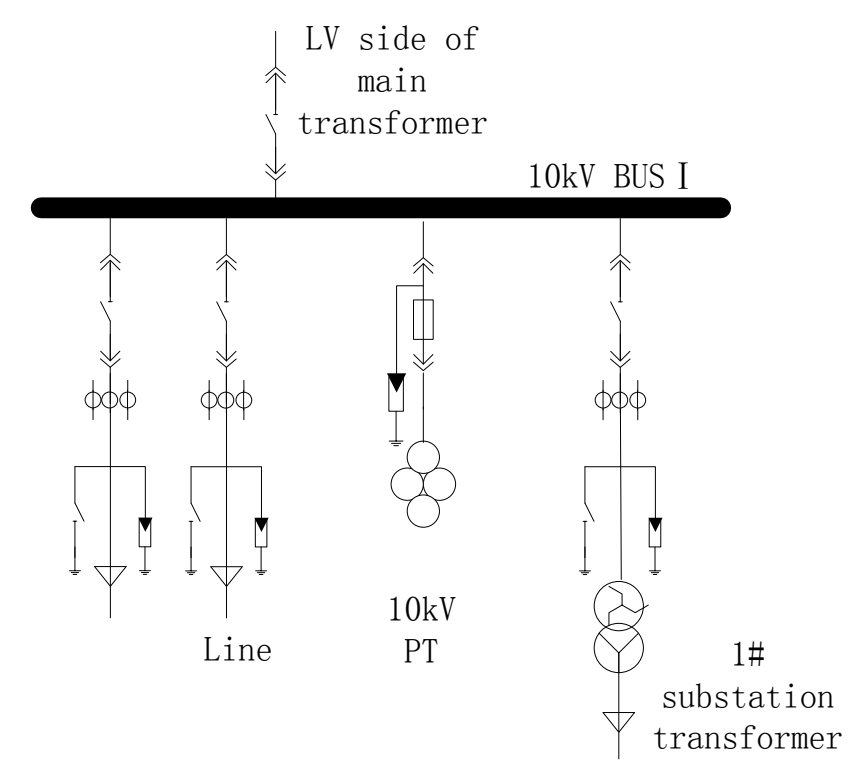

Figure 1. Substation Diagram

At $3 \mathrm{pm}$ on June 21st, the single phase to ground fault occurs in the substation. The operating personnel are ordered to carry out the fault line selection. After disconnected the fault circuit breaker, $10 \mathrm{kV}$ three-phase voltage disappear, monitor alarm at VT disconnection. Onsite inspections to confirm voltage transformer three-phase high-voltage fuse is blown. Maintenance of class test, replace the high-pressure insurance join operation, 3 phase voltage display normal.

At 10:00 on July 14 , at 18:00 on July 17 , the same substation single-phase ground fault occurs, the fault line selection phase high voltage caused by VT blown fuse again.

From May to September, the peak summer power stage, most of the urban substation high load even running at full capacity. High voltage fuse is blown, on the $10 \mathrm{kV}$ system loses surveillance, caused direct economic losses, and planted a huge accidents.

\section{ACCIDENT ANALYSIS}

\section{A. Power System Ferroresonance}

Power system neutral point grounding way is a related to the reliability of power supply, the size of the short circuit current, personal and equipment safety, over voltage, insulation level, the size of the configuration of relay protection and automatic device, electromagnetic 
environment compatible, communication interference as well as the system stability and so on many aspects of a comprehensive technical and economic problems [2, 3].

Power system with neutral grounding method are: no grounding, grounding resistance, reactance grounding, the arc suppression coil grounding, direct to wait for a few kinds. Non-ground neutral or is currently on the international via high impedance grounding, such as the arc suppression coil grounding system is called the effective grounding system, the neutral point grounding directly or via the small resistance grounding system is referred to as the effective grounding system. Direct grounding power system security is low, due to the singlephase earth fault occurs in the system, ground and neutral point can form a loop, thus grounded phase short circuit current is very big, at this time in order to prevent damage to electrical equipment grounding must be quickly removed. Not grounding system of single-phase grounding without the above phenomenon, thus improving power supply reliability, but not grounded phase voltage will be increased to 3 times of the original phase voltage, which require electrical equipment insulation level. So up to and including $35 \mathrm{kV}$ voltage level of system, adopt neutral point grounding way.

Neutral point grounding system, the PT high-voltage fuse fusing is mostly caused by PT ferromagnetic resonance produced. Instantaneity grounding fault disappear capacitor discharge according to the theory of analysis, the basic method is to reduce the occurrence ground fault transient surge after the capacitor discharge current. Single-phase earth fault, the system of the capacitor current through fault location, $10 \mathrm{kV}$ lines, PT a winding form closed loops, when the excitation inductance of PT and the parameters of the system to ground capacitance matching occurs when $\mathrm{L}$ - C ferroresonance, produce resonance overvoltage, make a current PT achieve several times to ten times the rated current, high voltage fuse fusing of PT.

The main solution from two aspects:

(1)Add bypass between PT and pick up location, line to ground capacitance stored in charge through the bypass line of the neutral point connected to ground, in order to reduce the influence of inrush current in the process of recovery. Specific measures for the system neutral point through the arc suppression coil grounding or through a grounding resistance.

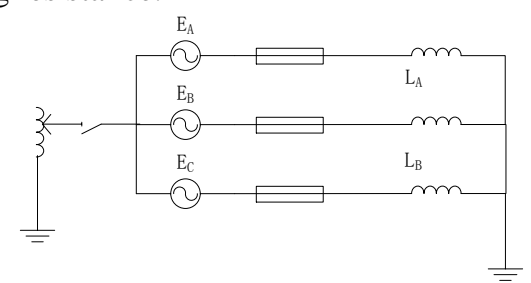

Figure 2. Neutral through Petersen Coil Grounding System Diagram

System neutral ground through the arc suppression coil, under the condition of resistance, the corresponding equivalent inductance, resistance of arc suppression coil impedance value less than the magnetizing inductance of PT, instant failover, most earth capacitance of electric charge through neutral arc suppression coil or discharge resistance to the earth, and the small by PT into the ground, can significantly reduce the influence of capacitor discharge of high-voltage fuse.

(2) Change the connection mode of PT, such as PT high side by the grounding resistance, the $4 \mathrm{PT}$ connection mode. After earth fault or failure recovery, on the voltage applied to the PT are smaller than the bus line voltage, reduce the voltage transformer on charge, and the high voltage fuse on the electrical transient current.

\section{B. PT by Nonlinear Resistance Grounded System Analysis}

The operation mode of the $10 \mathrm{kV}$ substation system for neutral point grounding, bus PT a winding neutral point for harmonic elimination protective grounding resistor.

On-site inspection equipment, high voltage withstand insurance for $12 \mathrm{kV}$, through traffic for $0.5 \mathrm{~A}$. $10 \mathrm{kV}$ bus VT primary winding neutral point installed resistive harmonic elimination device harmonic elimination LXQIII-10-type resistors, power is more than equal to $800 \mathrm{~W}$. The main parameters is shown in Table 1:

Tab 1. Main parameters of LXQIII-10

\begin{tabular}{lllll}
\hline $\begin{array}{l}\text { AC voltage } \\
\text { through }\end{array}$ & $\begin{array}{l}\text { AC resistor } \\
\text { through }\end{array}$ & $\begin{array}{l}\text { AC } \\
\text { voltage } \\
\text { through } \\
10 \mathrm{~mA}\end{array}$ & $\begin{array}{l}\text { AC } \\
\text { Resistor }\end{array}$ & $\begin{array}{l}\text { 2 hours } \\
\text { tolerance } \\
\text { power }\end{array}$ \\
\hline $838 \mathrm{VA}$ & $10 \mathrm{~mA}$ & $1 \mathrm{~mA}$ & powh \\
\hline
\end{tabular}

Wiring is shown in Figure 3:

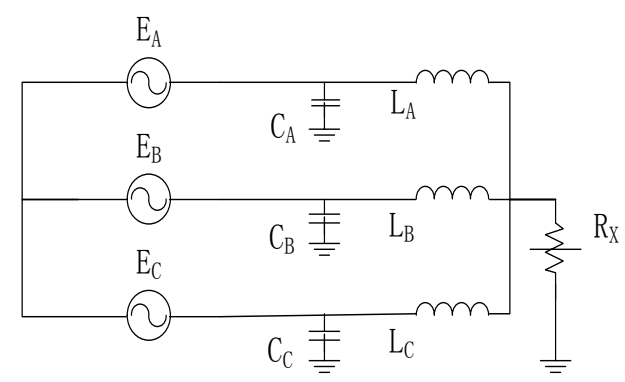

Figure 3. Harmonic Elimination Resistor Connection Diagrm

Harmonic elimination resistor role is mainly between the VT primary coil neutral points and add a large resistor, typically non-linear resistors, used to change the resonance parameters of the system, reducing the system's resonant current, or even completely eliminate the VT once coil inductance and the resonance effect on the capacitance between the grounds.

LXQIII-10-type resistors are composed by SIC plus special non-linear resistive material fired at high temperatures, a number of non-linear resistance through a combination of different ways link. In normal operation, due to the symmetry through three phase voltage, current flows through the neutral point is not, at this time harmonic elimination high-impedance state, undermining the resonance condition at the start. When single-phase ground fault, one phase voltage becomes zero, resulting in a large zero-sequence voltage, VT primary winding neutral-to-ground system as the only metal channel appears on the $\mathrm{kV}$ voltage harmonic elimination, by voltage characteristic curve shows the nonlinear resistor, 
then the resistance is low resistance state, the resistance drops thousands of Euro, harmonic elimination voltage across the smaller, and because the harmonic elimination of a large heat capacity, can better prevent arc grounding When damage to the equipment.

Inspection harmonic elimination resistor meet voltampere characteristic curve, the work is normal. So the PT fuse fusing not because PT excitation inductance and system of capacitance resonance effect.

Harmonic elimination resistor can produce better suppression system occurred when the single-phase ground fault arc grounding overvoltage. VT replacement while adding high-pressure insurance operating normally exclude secondary overload, VT winding insulation may be reduced.

Phylogenetic VT high voltage fuse blows when the fault current may be removed to produce low-frequency operation resulting in a saturation current VT high voltage fuse is blown.

\section{The Simulation Analysis}

When single-phase ground fault clearing instant, nonfault phase line will loop resistance to the charge on the capacitor discharge, forming power, the formation of the charge-discharge circuit. In the system, voltage transformer magnetizing inductance and capacitance to ground zero sequence to form an oscillation circuit. When an ultra-low frequency oscillation, transient saturation voltage transformer primary side, once an overcurrent on the winding $[4,5]$.

Single-phase ground fault occurs $10 \mathrm{kV}$ ungrounded system, the fault phase current increases as the load current and capacitance relative to all non-fault currents, operating personnel on-site inspection when the three-phase fault current is: $\mathrm{IA}=19.47 \mathrm{~A}, \mathrm{IB}=240.32 \mathrm{~A}, \mathrm{IC}=30.33 \mathrm{~A}$. Since the adoVTion $10 \mathrm{kV}$ substation cable outlet, has a large capacitance to ground, the measured capacitance to ground of approximately $120 \mu \mathrm{F}$.

Voltage transformer for JDJZ-10 epoxy pouring voltage transformer, its primary voltage value and the coil current value of test data in the Table 2 :

Tab 2. Test data sheet of JDJZ-10

\begin{tabular}{llllll}
\hline Voltage/kV & 4.0 & 5.0 & 5.5 & 6.0 & 6.5 \\
\hline Current/mA & 291.5 & 383.5 & 452.5 & 542.5 & 675 \\
\hline Voltage/kV & 7.0 & 7.5 & 8.0 & 9.0 & 11.0 \\
\hline Current/mA & 820 & 1000 & 1273 & 2050 & 5500 \\
\hline
\end{tabular}

Excitation curve is shown in Figure 4:

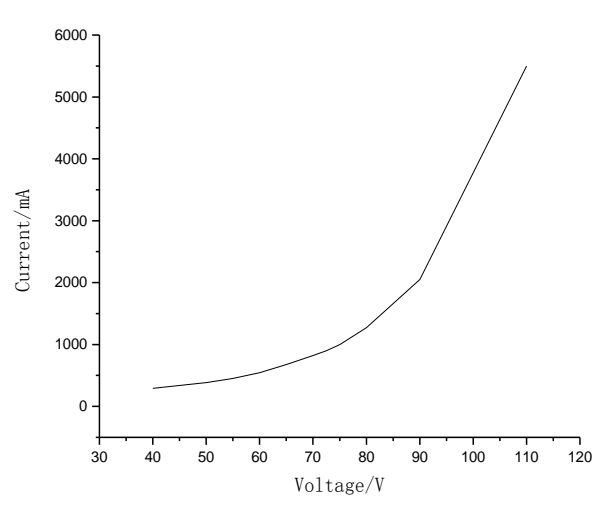

Figure 4. Excitation Curve of JDJZ-10

Fault current is cut off instantly, due to high voltage transformer neutral point offset, harmonic elimination resistor voltage across the high and low resistance. Take high-voltage transformers and simulation harmonic elimination resistor combined resistance of $1 \mathrm{k} \Omega$.

Use Multisim modeling, circuit simulation zero sequence is shown in Figure 5:

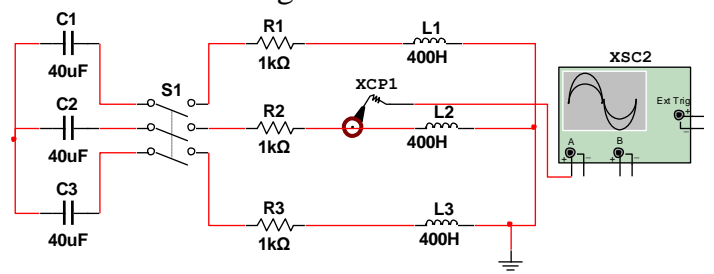

Figure 5. Schematic Simulation with Multisim

Figure $\mathrm{C} 1, \mathrm{C} 2, \mathrm{C} 3$ for $10 \mathrm{kV}$ system ground capacitance, $\mathrm{R} 1, \mathrm{R} 2, \mathrm{R} 3$ for three relatively resistors, $\mathrm{L} 1, \mathrm{~L} 2, \mathrm{~L} 3$ for the voltage transformer primary winding inductance, wherein the initial voltage of the capacitor is $10 \mathrm{kV}$. Current measurement probe ratio of $1 \mathrm{~V} / 1 \mathrm{~A}$.

The simulation results is shown in Figure 6:

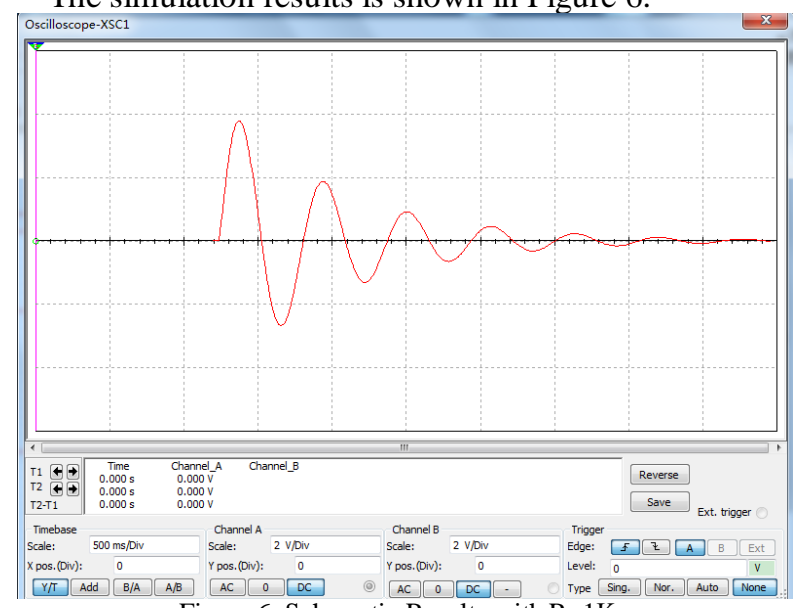

Figure 6. Schematic Results with $\mathrm{R}=1 \mathrm{K \omega}$

Obviously when the switch is closed momentary current increases, sustained concussion, the maximum is about 3.7A, far greater than the rated current of the highpressure insurance $(0.5 \mathrm{~A})$. $4 \mathrm{~s}$ peak in excess of $0.5 \mathrm{~A}$, long overcurrent thermal effects also cause high voltage fuse breaking VT.

Relative resistance to change three parameters, resistance to $10 \mathrm{k} \Omega$ simulation results is shown in Figure 7: 


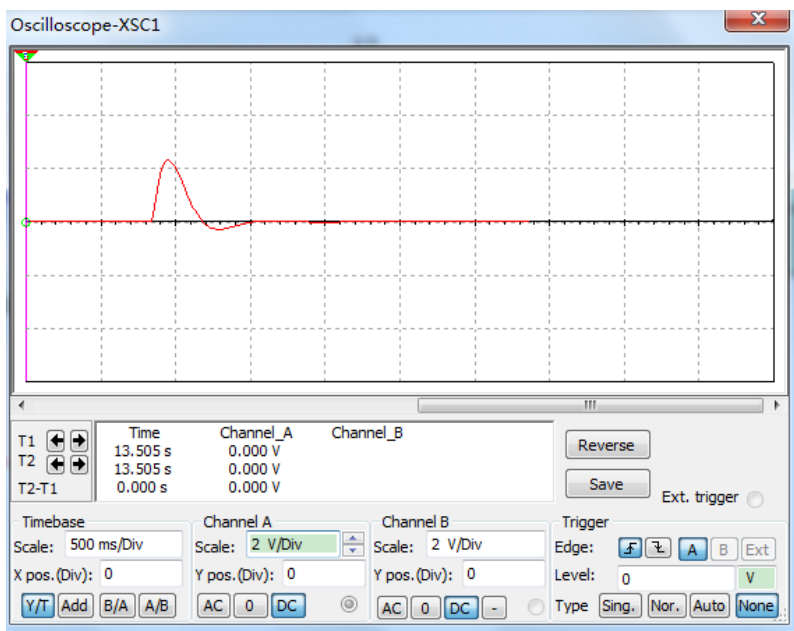

Figure 7. Schematic Results with $\mathrm{R}=10 \mathrm{k} \Omega$

Obviously, when three relatively resistance increases when the system can reduce low-frequency oscillating current. But resistance to ground is too large, easy loop charge into the earth, will the system insulation weak links strong impact. So, just to change the PT primary winding resistance to ground is not a solution PT fuse the best solution.

In order to eliminate the zero-sequence current low frequency oscillation can change $10 \mathrm{kV}$ neutral point grounding system. Neutral grounding or earth through the Petersen coil, can better compensate the capacitive current, while establishing a new path to ground, which greatly reduces the current through a neutral point PT. Which can greatly reduce the low-frequency shock because the zerosequence caused the accident frequency high voltage fuse breaking.

\section{SOLUTION}

In order to eliminate the zero sequence current low frequency oscillation, need to change the $10 \mathrm{kV}$ system neutral point grounding way. Neutral point grounding or via arc suppression coil grounding directly, can better compensate the capacitive current, at the same time, to build new pathways, to greatly reduce by PT a neutral point of current. Thus can greatly reduce because of the zero sequence of low frequency oscillation caused by high pressure safety fuse accident frequency. Directly grounded system reliability is low, the impact power user power supply continuity, so it is not recommended.

Adopt neutral point via arc suppression coil grounding, when a single-phase grounding power system, can reduce the current grounding, reduced the speed of recovery voltage and easy ground arc extinguishing, reduce and eliminate the intermittent arc over-voltage, improve the reliability of the power grid security.

Power system neutral point via arc suppression coil grounding, when single-phase earth fault occurs, smaller threat to personal safety. Because the system neutral point via arc suppression coil grounding, the single-phase earth fault occurs, the steady-state small grounding current, low voltage step and touch voltages of fault point and does not affect the security of person.

Due to the neutral point via arc suppression coil grounding to reduce the grounding current, reduce the damage to the equipment, make the single-phase grounding power system run safely, still without power, operating personnel to find out the fault within 2 hours. Guarantee the power system, uninterrupted power supply, greatly improve the safety and reliability of power supply.

Neutral point via arc suppression coil grounding, can avoid the ferromagnetic resonance caused by voltage transformer, no longer need to other harmonic elimination measures, because the arc suppression coil inductance compared with the voltage transformer excitation inductance is much larger, difference of several orders of magnitude, in zero sequence circuit, the inductance is parallel, excitation inductance of voltage transformer is short, almost destroyed the ferromagnetic resonance conditions.

Via arc suppression coil grounding, reduced the earth current, thus created the electromagnetic compatibility of the distribution network environment. Power line interference of electromagnetic fields for communication and signal system is quite serious, every article - ac line space around the alternating electromagnetic field is established, and alternating electromagnetic field and induced voltage in the neighboring conductor loop. When the loop in the communication lines near the power line communication or signal system, the induction voltage may cause serious interference, and even endanger the safety of the staff or cause signal device. Arc suppression coil grounding method, because the arc suppression coil grounding, changed the system parameters, make comprehensive zero sequence impedance, so it is not easy to cause the audio interference, even if the overhead line break line, to lead, or may not cause personal injury. When single-phase earth fault occurs in power system, the grounding current distribution and the fault location, and depends on the installation site, and the relative position of arc suppression coil, can try to adjust the distribution of earth current, to offset the electromagnetic induction.

\section{CONCLUSIONS}

Based on the analysis on the basis of high-voltage transformer blown fuse together $10 \mathrm{kV}$ ungrounded system, single-phase ground fault caused by the removal, the effects of harmonic elimination resistor to ground fault current at the time of removal, and the proposed change to solve the neutral point system grounding mode is the best option.

\section{REFERENCE}

[1] Guangrun Xie. Overvoltage power system [M]. Beijing: China Water Power Press, 1985.

[2] Su Ji-feng. Distribution network neutral point grounding way research [J] Power System Protection and Control, 2013, 08.

[3] Zhiping Chen, Xiangchao Jin. $10 \mathrm{kV}$ voltage transformer fuse electromagnetic frequently burned accident analysis [J] China Southern Power Grid Technology, 2009, 3.

[4] Qi Zheng,Dong Di,Yang Yihan.Single-phase grounding neutral point grounding system ferro-resonance and identification technology[J] Automation of Electric Power Systems, 2010, 01.

[5] Shaoyu Chen, Dong Ge, Hui Chang, etc. Calculation of ultra-low frequency oscillation distribution network simulation $[\mathrm{J}]$. High Voltage Engineering, 2004, 30 (5): 18-22. 